\title{
Identity, Voice, Community: New African Immigrants to Kansas
}

Final Report to the Kansas Humanities Council

June 30, 2006

Kansas African Studies Center

John M. Janzen, Director

Here is the final report of the project

We believe that this project is important because Kansans and Americans need to know who the new African immigrants are, why they left home, why they have come here, and what distinctive human perspectives and practices they contribute to American society. Our project is one of civic education and cultural awareness raising. As the only African Studies Center in Kansas -and the Central Plains--we believe we can fulfill our mandate of educating the public about Africa by getting better acquainted with the new African immigrants who are also our new neighbors and fellow citizens.

All in all, the project ran more or less as it was planned, although most aspects took longer than anticipated. A team of Center affiliated faculty, staff, and graduate students interviewed project partners and others in their communities. We held two public meetings in spring 2006 that raised important issues and produced rich narratives. Along the way photo work was done of the project and in the communities. All materials generated by the project, detailed at the end of this report, will be deposited with the Kansas Collections at the Spencer Research Library at KU, and offered to KHC.

\section{Perspectives on Migration, Research, and Public Programming}

Migration is an old American phenomenon. Most Americans have a history of immigration in their background. Yet today migration scholarship frames this phenomenon in global perspective, as much as a local, state, or national perspectives.

Even the term "transnational migration" reflects an effort to transcend the boundaries of territories, societies, states and nations to grasp the dynamic characteristics of migration and the continuing transnational identities that ensue for those who move from one nation-state to another, or continue shuttling back and forth, or have long-term hyphenated identities. Scholarship focuses on transnational flows of people and capital, on the "push" of war, poverty, and persecution, and "pull" factors of economic opportunity, education, and religious freedom.

Because of the makeup of the team, disciplinary perspectives from anthropology, geography, and education influenced the way the research dimension was done. John Janzen, project director and PI, a sociocultural anthropologist, working with Melissa Filippi-Franz, a graduate student in anthropology, developed interview protocols. Janzen, Filippi-Franz, and Khalid Elhassan, PhD, Center Program Coordinator, and Project co-PI, conducted related interviews. Garth Myers, Associate Professor of Geography and Associate Director of the Center, used methods from his discipline, together with a $\mathrm{PhD}$ former student of his Mohamed Dosi Mohamed, Zanzibari-American, and another Tanzanian-American, Ass't Professor of Swahili, Leonce Rushubirwa. These individuals 
conducted intensive research and group interviews in several days with this community in Wichita and Kansas City. Khalid Elhassan, a Sudanese-American, with a PhD in Education and African Studies, was involved with the Sudanese community in particular and also provided his disciplinary perspective in the public programming. Later in the project, political science student and Center intern Abdulrahme Gitale worked closely with the Somali community. The multi-disciplinary representation of the team gave the project both depth and breadth in its coverage. Humanists David Katzman added perspectives of history and American Studies, and Omofolabo Ajayi added the perspective of performance studies and Women's Studies.

From the start this project was run in the manner that anthropologists would term Collaborative Ethnography. That means the participants were involved in many of the decisions along the way. Some of the participants were the very individuals who had been invited by Elhassan to participate in the African Studies Seminar in fall 2004. The project in fact grew out of participants' suggestions of what they would like to see the Center do with and for them. We circulated the proposal and word of its funding to all of our partners so that they would understand what we were planning, and that they could expect us to be in contact with them. We next tested our questionnaire on about three interviewees, and made some adjustments, before the larger number were conducted. The brochure became one of our main tools for publicity. Our Center website also has a section devoted to the project.

Interviews were conducted by project personnel, including the project director, Khalid Elhassan, Garth Myers, and, the great majority, Melissa Filippi-Franz, a graduate student in anthropology who was paid KHC support for this. New African Language Professor Leonce Rushubirwa, a Tanzanian-American, collaborated with Garth Myers in the study of the Tanzanian and Zanzibari communities of Kansas City and Wichita.

The public meetings were postponed to spring, 2006, from their earlier schedule time in late fall 2005. This was due to the still un-transcribed interviews and individuals still needing to be interviewed. By spring 2006 the interviews had been mostly transcribed and our two guest humanists, Omofolabo Ajayi, and David Katzman, could read the texts to prepare for their comments. Prior to both public meetings the project director invited participants, humanists, and a few guests to a reception at a nearby restaurant, where African or Middle Eastern food provided the ambience to become better acquainted. Prior to the public meeting at the Lawrence Public Library on March 27 we met at the Alladin Café on Massachusetts Street. Prior to the May 1 meeting at the Jewish Vocational Services in Kansas City we met at the African Market on Main Street. About 25 persons attended the Lawrence Public Library meeting, and about 35 the Kansas City meeting at the Jewish Vocational Services.

\section{Products of the Project}

All the following products of the project will be deposited with the Kansas Collection of the Spencer Research Library at the University of Kansas. 
- Interview protocols and interview texts, and a CD copy of the audiotrack will be deposited with the Kansas Collection of the Spencer Research Library at the University of Kansas (see table of contents and the Interview Protocols in attached files);

- Transcriptions of the public meetings are being prepared, which include the comments by humanists Omofolabo Ajayi and David Katzman (transcriptions and videofilm of meetings will be submitted to the Spencer);

- "Tanzanians in the Land of Oz", by Dosi, Rushubirwa, and Myers, a paper submitted to Social and Cultural Geography in February 2006 and now in press;

- Several hours of videotape and many digital still photograps, on CD (see attached file listing inventory of photo material);

- The videofilm "Identity, Voice, Community: New African Immigrants to Kansas" to be ready by early fall 2006 (see videofilm story line and photo listing in attached file);

\section{Findings and Reflections}

The interviews allow for more systematic analysis and reporting than is possible in the format of the project. Here are some unscientific findings and reflections on the new African immigrants to Kansas.

1. Close to 10,000 "new" African immigrants of the past twenty years and their children born in the U.S. today reside in U.S. heartland metropolitan centers of Kansas City and vicinity, Lawrence, Topeka, Emporia, and Wichita. General numbers gleaned from interviews with community leaders, extrapolations from census figures, and some guesswork, provide the following details: Somalis, who came mainly as refugees, and live in the Kansas City region, are probably the largest community, with about 4-5,000, suggests Farah Abdi, founder and director of the Somali Foundation; Kenyans, for the most part successful business people, or students become professionals, are living in Wichita, Topeka, and Kansas City, numbering perhaps one to two thousand; Nigerians, more numerous than project participants would indicate, having come over the years as political asylees, students and professionals, number perhaps several (2-3) thousand in Kansas' largest cities; Tanzanians, including the prominent Zanzibari group in Wichita, and others in Topeka, Lawrence, and Kansas City, number around 500; Ethiopians have resided in Kansas City and Wichita for a decade or more, the result of civil war, repression, and drought/famine, with perhaps 500 in all; Sudanese of the north, the middle region, the south, and most recently the west, have come often as refugees and political asylees. In some cases, such as Akot Arec's community building effort in Olathe, altogether the Sudanese of Kansas' urban centers may number 750 to a thousand. Sierra Leonians have come as refugees following that country's civil war, but numbers remain a few hundred.

2. The new African immigrants come for many reasons, under many circumstances: they are political asylum seekers, refugees, students, or those seeking opportunity in their chosen work. However, often they are disappointed not to find work in their area of training, especially if trained in Africa-e.g., professionals, doctors, 
teachers, researchers. They often find work in the service sector, as taxi drivers, orderlies, etc.;

3. Reasons for migrating varied, but several categories of motives were given or could be inferred: to seek political asylum from persecution; to escape war and to seek a new home, the refugee experience; new opportunity, economic, professional;

4. The overwhelming majority of the new African immigrants are upright, lawabiding respectful persons - one observer said "Africans are the most legal of all the immigrants to the U.S." Yet circumstances often force new immigrants to compromise or even break laws to survive-e.g., work without a permit, use forged identity documents;

5. Faced with many perplexing challenges and issues, the new African immigrants do what immigrants have done historical, they create self-help organizations to negotiate the bureaucratic maze with which they confronted, and to make connections to work, residence, and educational opportunities. The interviews, publications, and videofilm feature several of these organizations such as the Somali Foundation of Kansas City; churches, mosques, and clubs have been organized to formalize these new communities, or existing religious and voluntary organizations have become homes for African spiritual devotion and the desire for socializing conviviality;

6. Immigrant organizations and networks often reflect the political alliances and fractures of the home country or situation-e.g., the fractures of a civil war, the religious divide, class divisions (Sudan's representatives at the Kansas City public meeting); but this situation then also calls forth the desire to break with the fractures of the home country and to strive for unity in the United States;

7. New African immigrants arrive in the U.S. and discover that they are suddenly generic "African" or "black" or "African-American." They are uncomfortable with these new identities that American society thrusts upon them, especially to be associated with African-American. Jane Irungu's eloquent account in the Lawrence public meeting of her encounters with U.S. census categories was both humorous and revealing. The many ways that identity is negotiated and recreated are a fruitful area of story and further research;

8. "Why Kansas?" (or Kansas City) surfaced in many immigrants' stories, in part in answer to the question, often spontaneously. Life is more straight-forward in the Midwest than in big cities of the East; educational opportunities are available more advantageously; raising families is possible; in a few case like the Zanzibari-American Association, the national headquarters is in Kansas;

9. The participants hope that their involvement in this project will give them solutions to their problems, but realistically, several of them observed that the most likely benefit to them would be to gain positive visibility in American society. Often they would speak of the gap in knowledge of Africa on the part of Americans, and occasionally they mentioned prejudice they had encountered, they thought born of ignorance. To this end, in addition to the documentation we have created in this project, the main thrust of the videofilm or related material will be for public education. A next phase of the project may address some of the issues surrounding the educational needs of immigrants, especially the teen-age youth. 
